\title{
The Association Between Asthma and Narcolepsy: A Nationwide Case-Control Study in Taiwan
}

Tien-Yu Chen, (D) ${ }^{1-3, *}$ Vincent Yi-Fong $\mathrm{Su},(\mathbb{D}){ }^{4,5}, *$ Chung-Hsin Lee, ${ }^{6}$ Chi-Hsiang Chung, (D) ${ }^{7-9}$ Chia-Kuang Tsai, ${ }^{3,10}$ Chung-Kan Peng, (iD ${ }^{3,1}$ I Hsiao-Ching Lai, ' Wu-Chien Chien, ${ }^{7-9,12}$ Nian-Sheng Tzeng (iD) ${ }^{1,13}$

'Department of Psychiatry, Tri-Service General Hospital, School of Medicine, National Defense Medical Center, Taipei, Taiwan; ${ }^{2}$ Institute of Brain Science, National Yang Ming Chiao Tung

University, Taipei, II2, Taiwan; ${ }^{3}$ Sleep Medicine Center, Tri-Service General Hospital, School of Medicine, National Defense Medical Center.

Taipei, Taiwan; ${ }^{4}$ Department of Internal Medicine, Taipei City Hospital, Taipei, Taiwan; ${ }^{5}$ Faculty of Medicine, School of Medicine, National Yang Ming Chiao Tung University, Taipei, I I2, Taiwan; ${ }^{6}$ Department of Neurosurgery, Neurological Institute, Taichung Veterans General Hospital, Taichung, Taiwan; ${ }^{7}$ Department of Medical Research, Tri-Service General Hospital, National Defense Medical Center, Taipei, Taiwan; ${ }^{8}$ School of Public Health, National Defense Medical Center, Taipei, Taiwan; ${ }^{9}$ Taiwanese Injury Prevention and Safety Promotion Association, Taipei, Taiwan; ${ }^{10}$ Department of Neurology, TriService General Hospital, School of Medicine,

National Defense Medical Center, Taipei, Taiwan;

"Division of Pulmonary and Critical Care Medicine, Department of Internal Medicine, TriService General Hospital, School of Medicine, National Defense Medical Center, Taipei, Taiwan; ${ }^{12}$ Graduate Institute of Life Sciences, National Defense Medical Center, Taipei, Taiwan; ${ }^{13}$ Student Counseling Center, National Defense Medical

Center, Taipei, Taiwan

*These authors contributed equally to this work

Correspondence: Wu-Chien Chien Department of Medical Research, Tri-Service General Hospital, National Defense Medical Center, 7II5R, No. 325, Section 2, Cheng-Kung Road, Neihu District, Taipei, I 1490, Taiwan

Tel +886 2-879233 I I, Ext. 19189

$\mathrm{Fax}+886$ 2-87927235

Email chienwu@mail.ndmctsgh.edu.tw

Nian-Sheng Tzeng

Department of Psychiatry, Tri-Service General Hospital, National Defense Medical Center, 325,

Section 2, Cheng-Kung Road, Neihu District, Taipe

City, I 1490, Taiwan

$\mathrm{Tel}+8862-87927299$

Fax +886 2-87927221

Email pierrens@mail.ndmctsgh.edu.tw
Purpose: Asthma, which is caused by inflammation of the airways, affects the sensitivity of nerve endings. Narcolepsy is a chronic sleep disorder that may be caused by autoimmunity. Recent studies have reported a positive association between narcolepsy and asthma. We aimed to examine the association between asthma and narcolepsy and determine the effects of therapeutic corticosteroid or bronchodilator use.

Materials and Methods: We conducted a nationwide population-based, nested casecontrol study using Taiwan's National Health Insurance Research Database (NHIRD) between 2000 and 2013. Subjects with narcolepsy (ICD-9-CM code 347) were enrolled, with 1:3 estimated propensity score-matched controls based on sex, age, and index year. The association between narcolepsy and asthma was assessed using multiple logistic regression analyses. The covariates included sex, age, monthly insurance premiums, geographical area of residence, urbanization level of residence, level of care, and presence of diseases related to immune response and central nervous system. The effects of corticosteroid and bronchodilator use were also analyzed.

Results: Overall, 2008 subjects were identified from the NHIRD (502 patients with narcolepsy and 1506 controls). The participants with narcolepsy had almost three times the level of previous asthma diagnosis than controls. Compared to those without asthma, patients with asthma had an adjusted odds ratio (OR) of 3.181 for narcolepsy comorbidity (95\% confidence interval [CI]: $2.048-4.941, p<0.001)$. The use of inhaled corticosteroids was associated with a lower risk of narcolepsy comorbidity, with an adjusted OR of 0.465 (95\% CI, $0.250-0.634 ; p<0.001$ ), in patients with asthma when compared to those without treatment. Conclusion: This study demonstrated a significantly higher level of previous asthma diagnosis in patients with narcolepsy. The use of inhaled corticosteroids was associated with a lower risk of narcolepsy comorbidity in asthma patients, compared to those without treatment.

Keywords: asthma, narcolepsy, corticosteroid, bronchodilators

\section{Introduction}

Narcolepsy is a neurological disorder that affects the brain's ability to control sleep and wakefulness. There are two main types of narcolepsy: type 1 and type $2 .{ }^{1-3}$ All types of narcolepsy may cause excessive daytime sleepiness, sleep paralysis, hypnagogic/hypnopompic hallucination, early rapid eye movement (REM) sleep, and fragmented sleep. The difference between type 1 and type 2 narcolepsy is that the former may cause sudden loss of muscle tone (cataplexy). ${ }^{1-3}$ Multiple factors may be related to the pathophysiology of narcolepsy. Besides impaired function due to excessive daytime sleepiness, the high incidence of comorbidities, including mood disorders and other sleep disorders, affects daily function ${ }^{4-7}$ and may 
contribute to incidents such as motor vehicle accidents. ${ }^{6,8,9}$ A previous review reported a delayed diagnosis of narcolepsy by up to 15 years. ${ }^{10}$ Although variables associated with delayed narcolepsy diagnosis have been identified, a lack of symptom recognition and the abovementioned comorbidities can result in misdiagnosis prior to the final narcolepsy diagnosis. ${ }^{10-13}$

Asthma is a chronic inflammatory lung disease with exacerbation, which may contribute to morbidity and mortality. ${ }^{14-16}$ Several recent studies have reported a positive association between narcolepsy and asthma. Early REM sleep and fragmented sleep in narcolepsy can cause irregular respiratory responses and result in breathing disorders, such as asthma. ${ }^{17}$ Asthma and narcolepsy are considered to share common immunopathological mechanisms. ${ }^{18,19}$ One study reported that the prevalence of comorbid immunopathological diseases is high in patients with narcolepsy and that cataplexy is significantly more severe in patients with comorbid immunopathological disease and narcolepsy. ${ }^{20}$ Another study conducted by Aydinoz et al reported contrasting results in childhood narcolepsy; they found that the frequency of allergic conditions, particularly asthma and allergic rhinitis, was markedly lower in type 1 narcolepsy than in type 2 narcolepsy. ${ }^{21}$ Alomar et al, in a study from Saudi Arabia, enrolled 80 consecutive patients with narcolepsy and found that allergic disorders were associated with both type 1 and type 2 narcolepsy. ${ }^{22}$ Since most of the results reported to date are controversial and no nationwide population-based study has clarified the association between asthma and narcolepsy, the present study aimed to investigate the association between asthma and narcolepsy in Taiwan using the National Health Insurance Research Database (NHIRD), a nationwide population-based claims database.

\section{Materials and Methods}

\section{Data Source}

The National Health Insurance (NHI) Program was launched in Taiwan in 1995. As of June 2009, the program had established contracts with $97 \%$ of medical providers with approximately 23 million beneficiaries, accounting for more than $99 \%$ of the entire population. Details of the program have been provided in previous reports. ${ }^{6,7,23-28}$ The NHIRD contains all the claims data of the beneficiaries, and it uses the International Classification of Diseases, 9th Revision, Clinical
Modification (ICD-9-CM) codes to record the diagnoses. The accuracy of diagnoses recorded in the NHIRD, such as pneumonia, ${ }^{25}$ asthma, ${ }^{29}$ sleep apnea, ${ }^{30}$ and tuberculosis, ${ }^{31}$ has been validated.

A subset of the NHIRD, the Longitudinal Health Insurance Database (LHID), which consists of the data of 1 million randomized population samples accrued between 2000 and 2013, was used to study the association between asthma and the risk of narcolepsy. The Institutional Review Board of the Tri-Service General Hospital approved this study and waived the requirement for written informed consent (IRB No. 2-107-05-026).

\section{Study Design and Sampled Participants}

To undertake this population-based, retrospective casecontrol study, we included subjects aged $\geq 6$ years diagnosed with narcolepsy, based on the ICD-9-CM code (347), by board-certified sleep medicine specialists, including neurologists, psychiatrists, pulmonologists, and otorhinolaryngologists, between January 1, 2000, and December 31, 2013. The exclusion criteria were as follows: (1) age of $<6$ years on the study entry date and (2) unknown sex. The patients with narcolepsy and the control subjects were selected using a 1:3 estimated propensity score-matching based on sex, age, and index year.

\section{Major Outcome Measure}

The study aimed to evaluate the association between asthma and narcolepsy. Previous asthma diagnosis was investigated in both the narcolepsy and control groups. Each enrolled subject with asthma was required to have had at least six outpatient clinic visits or one hospitalization during the study period with a diagnosis code of 493 . This method used in this study to choose the subjects with asthma was validated in a previous study with $92 \%$ sensitivity. ${ }^{29}$ Figure 1 shows a detailed flowchart of the subject selection process.

\section{Potential Confounders}

The covariates included sex, age group (6-11, 12-19, 20$44,45-64$, and $\geq 65$ years), monthly insurance premium (in New Taiwan Dollars [NT\$]; <18,000, 18,000-34,999, and $\geq 35,000$ ), geographical area of residence (northern, central, southern, eastern Taiwan, and the outer islands), urbanization level of residence (levels 1-4), and level of care (medical center, regional, and local hospital). The urbanization level of residence was defined based on the population and various indicators of the level of 


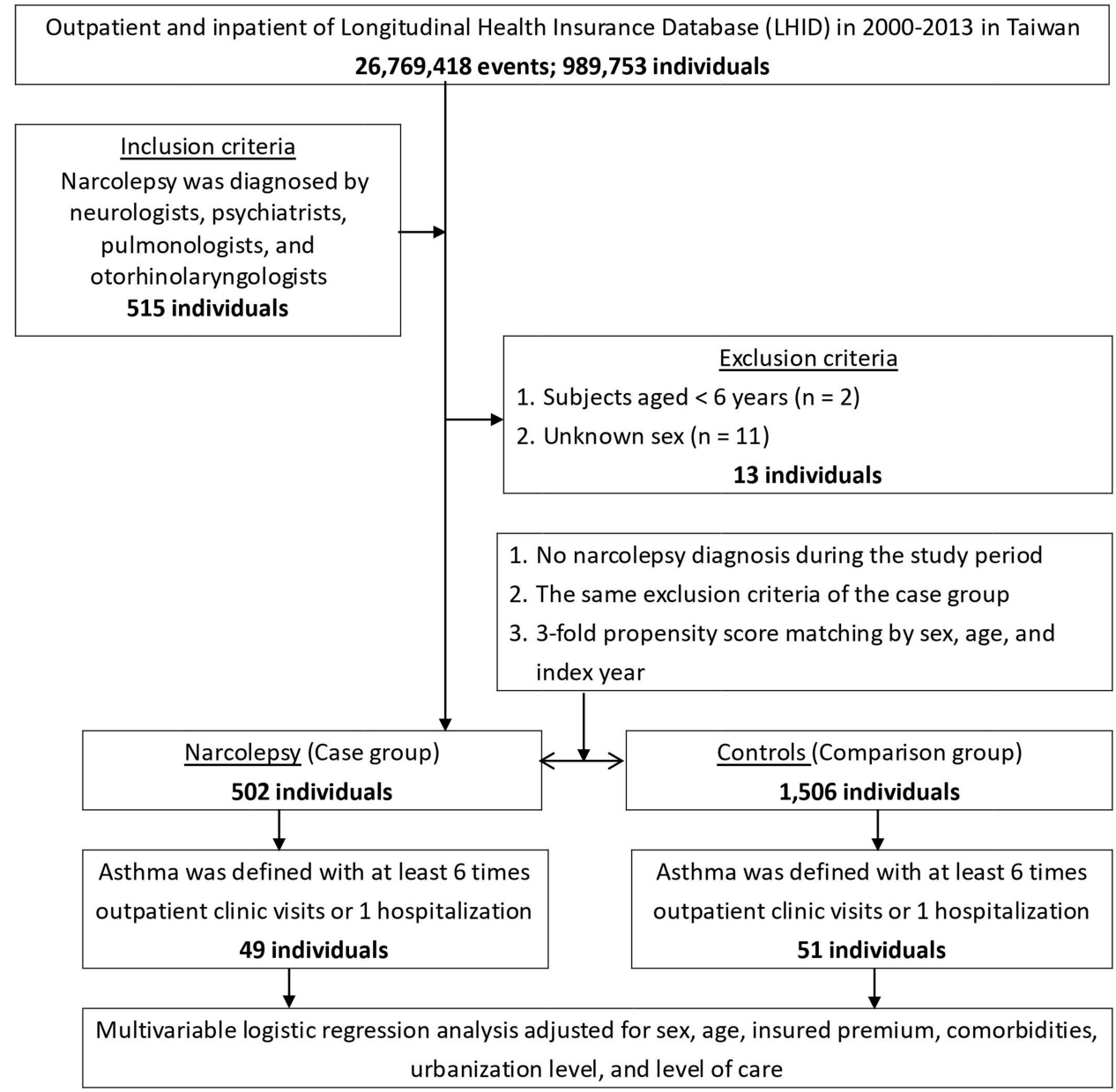

Figure I Flowchart outlining the sample selection procedure from Taiwan's National Health Insurance Research Database.

development. Level 1 was characterized by a population of $>1,250,000$ individuals in a region with political, economic, cultural, and metropolitan development. Level 2 was characterized by a population of $500,000-1,249,999$ individuals, with the area playing an important role in politics, economy, and culture. Urbanization levels 3 and 4 were characterized by populations of $149,999-499,999$ and $<149,999$ individuals, respectively. ${ }^{32}$

Several confounders may be associated with asthma and narcolepsy. We selected several diseases related to immune response, such as atopic dermatitis, allergic rhinitis, influenza, and autoimmune diseases, as confounding factors because of the possible immune impacts on both asthma and narcolepsy. Diseases related to the central nervous system (CNS), such as psychiatric disorders, CNS infection, cerebral palsy, obstructive sleep apnea (OSA), and insomnia, were also selected as confounders due to their possible impacts on sleep and breathing. These factors were assessed in the year preceding the study entry year. The concomitant use of medications for obstructive lung diseases, such as inhaled/oral/injected corticosteroids and bronchodilators, was also evaluated.

\section{Statistical Analysis}

All statistical analyses were performed using SPSS for Windows (version 22.0; IBM Corp., Armonk, NY, USA). The distributions of age, sex, and comorbidities in the patients with narcolepsy and the controls were evaluated using the Chi-square test. Multivariate logistic regression analyses were used to calculate the odds ratios (ORs) with 95\% confidence intervals (CIs; 95\% CI) to assess the association between asthma and narcolepsy, after adjusting for the potential confounding effects of comorbidities. Our logistic regression analyses used narcolepsy diagnosis as the dependent variable and other clinical predictors or potential confounders as the independent variables. Subgroup analyses for evaluating the association between asthma diagnosis and the risk of narcolepsy were 
conducted after stratification based on sex, age, and comorbidities. Logistic regression analysis was used to assess the association between medications used for obstructive lung diseases in asthma patients and narcolepsy comorbidity. Statistical significance was set at $p<0.05$.

\section{Results}

In this study, 2008 subjects were enrolled (502 subjects with narcolepsy and 1506 subjects without narcolepsy). Table 1 shows the sex, age, monthly insurance premiums, comorbidities, area of residence, urbanization level, level of care, and medication use for obstructive lung diseases in narcolepsy patients and controls. Compared with the controls, a higher proportion of narcoleptic patients tended to have asthma, psychiatric disorders, CNS infection, OSA, and insomnia, but a lower proportion of the patients had influenza; they also had a higher likelihood of living in urbanization levels 1 or 2 and in the northern region and outer islands of Taiwan. In addition, narcoleptic patients tended to have a higher likelihood of inhaled/oral/injected corticosteroid use.

Table 2 shows the outcomes of multivariate logistic regression analysis of the factors associated with the risk of narcolepsy comorbidity. Compared with patients without asthma, those with asthma had a crude OR of $3.086(95 \%$ CI, 2.056-4.631; $p<0.001)$ for narcolepsy comorbidity. After adjusting for sex, age, monthly income, atopic dermatitis, allergic rhinitis, allergic conjunctivitis, psychiatric disorders, CNS infection, cerebral palsy, OSA, insomnia, influenza, autoimmune diseases, geographical area of residence, urbanization level of the residence, and level of care, the adjusted OR was 3.181 (95\% CI, 2.048-4.941; $p<0.001)$.

Table 3 shows the effects of medication use on the association between asthma and narcolepsy comorbidity. Compared with the patients in the asthma group who did not use medication, those who used only inhaled corticosteroids had an adjusted OR of 0.465 (95\% CI, 0.250$0.634 ; p<0.001)$ for narcolepsy comorbidity; no significant difference was observed for the bronchodilator-only group among the patients with asthma.

\section{Discussion}

\section{Asthma, Narcolepsy, and Corticosteroid Use}

This study reports several noteworthy findings. First, previous asthma diagnosis in patients with narcolepsy was almost three times higher than that in the controls. In contrast to previous studies on the relationship between asthma and narcolepsy, ${ }^{17,20-22}$ we used a nationwide claims database and a larger sample. Second, compared to those without asthma, patients with asthma had an adjusted OR of approximately 3.181 for narcolepsy comorbidity. Third, we investigated the effects of corticosteroid and bronchodilator use and found that the use of inhaled corticosteroids, as opposed to bronchodilators, was associated with a lower risk of narcolepsy comorbidity in patients with asthma. To the best of our knowledge, this is the first study to examine the association between asthma and narcolepsy and the effects of medication use for obstructive lung diseases in asthma using a nationwide population-based database.

Compared with previous studies on the association between asthma and narcolepsy, this study has several key points. First, it was a retrospective case-control study that used a large nationwide database, when compared with other retrospective chart reviews that used small sample sizes. ${ }^{20,21}$ Second, we exclusively examined the association between asthma and narcolepsy instead of analyzing the relationship between several sleep disorders and allergic diseases. ${ }^{17,20,21}$ Third, we examined the effects of inhaled corticosteroids on the risk of narcolepsy comorbidity in patients with asthma; the results showed an almost 50\% decrease of narcolepsy comorbidity compared with those without medication use.

Previous studies have reported that corticosteroid treatment for patients with asthma may decrease the risk of asthma-related death, ${ }^{33}$ lung cancer, ${ }^{34}$ and chronic kidney disease (CKD). ${ }^{23}$ However, some studies have found that the effects of corticosteroids vary with other diseases such as cancer, schizophrenia, and dry eye syndrome. ${ }^{35-37}$ A larger clinical trial for asthma patients using corticosteroids or other medications is therefore needed to confirm this association.

\section{Potential Mechanisms of the Association Between Asthma and Narcolepsy}

The "orchestration" of pro-inflammatory cytokines plays an important role in the pathogenesis of allergy-related diseases such as asthma. ${ }^{38}$ T-helper lymphocytes, key factors in the pathogenesis of asthma, can induce B cells to synthesize and secrete immunoglobulin E through the production of interleukin-4. Histamine, prostaglandins, leukotrienes, and kinins also contribute to the pathogenesis of 
Table I Characteristics of Study at the Baseline

\begin{tabular}{|c|c|c|c|c|c|c|c|}
\hline \multirow[t]{2}{*}{ Variables } & \multicolumn{2}{|c|}{ Total } & \multicolumn{2}{|c|}{ Narcolepsy } & \multicolumn{2}{|c|}{ Controls } & \multirow[t]{2}{*}{$P$} \\
\hline & $\mathbf{n}$ & $\%$ & $\mathbf{n}$ & $\%$ & $\mathbf{n}$ & $\%$ & \\
\hline Total & 2008 & & 502 & 25.00 & 1506 & 75.00 & \\
\hline Previous Asthma Diagnosis & 100 & 4.98 & 49 & 9.76 & 51 & 3.39 & $<0.001$ \\
\hline Sex & & & & & & & 0.999 \\
\hline Male & 1200 & 59.76 & 300 & 59.76 & 900 & 59.76 & \\
\hline Female & 808 & 40.24 & 202 & 40.24 & 606 & 40.24 & \\
\hline Age (years) & \multicolumn{2}{|c|}{$43.53 \pm 24.29$} & \multicolumn{2}{|c|}{$42.46 \pm 24.57$} & \multicolumn{2}{|c|}{$43.88 \pm 24.20$} & 0.255 \\
\hline Age group (years) & & & & & & & 0.999 \\
\hline $6-11$ & 112 & 5.58 & 28 & 5.58 & 84 & 5.58 & \\
\hline $12-19$ & 420 & 20.92 & 105 & 20.92 & 315 & 20.92 & \\
\hline $20-44$ & 608 & 5.58 & 152 & 5.58 & 456 & 5.58 & \\
\hline $45-64$ & 352 & 5.58 & 88 & 5.58 & 264 & 5.58 & \\
\hline$\geq 65$ & 516 & 25.70 & 129 & 25.70 & 387 & 25.70 & \\
\hline Insurance premium (NT\$) & & & & & & & 0.993 \\
\hline$<18,000$ & 1598 & 79.58 & 400 & 79.68 & 1198 & 79.55 & \\
\hline $18,000-34,999$ & 247 & 12.30 & 61 & 12.15 & 186 & 12.35 & \\
\hline$\geq 35,000$ & 163 & 8.12 & 41 & 8.17 & 122 & 8.10 & \\
\hline Atopic dermatitis & 2 & 0.10 & 0 & 0.00 & 2 & 0.13 & 0.414 \\
\hline Allergic rhinitis & 6 & 0.30 & 0 & 0.00 & 6 & 0.40 & 0.347 \\
\hline Psychiatric disorders & 186 & 9.26 & 87 & 17.33 & 99 & 6.57 & $<0.001$ \\
\hline CNS infection & 11 & 0.55 & 6 & 1.20 & 5 & 0.33 & 0.034 \\
\hline Cerebral palsy & 15 & 0.7 & 7 & 1.39 & 8 & 0.53 & 0.069 \\
\hline OSA & 25 & 1.25 & 21 & 4.18 & 4 & 0.27 & $<0.001$ \\
\hline Insomnia & 37 & 1.84 & 28 & 5.58 & 9 & 0.60 & $<0.001$ \\
\hline Influenza & 23 & 1.15 & I & 0.20 & 22 & 1.46 & 0.026 \\
\hline Autoimmune diseases & 14 & 0.70 & 4 & 0.80 & 10 & 0.66 & 0.759 \\
\hline Location & & & & & & & $<0.001$ \\
\hline Northern Taiwan & 863 & 42.98 & 296 & 58.96 & 567 & 37.65 & \\
\hline Middle Taiwan & 559 & 27.84 & 88 & 17.53 & 471 & 31.27 & \\
\hline Southern Taiwan & 458 & 22.81 & 79 & 15.74 & 379 & 25.17 & \\
\hline Eastern Taiwan & 108 & 5.38 & 28 & 5.58 & 80 & 5.31 & \\
\hline Out islands & 20 & 1.00 & 11 & 219 & 9 & 0.60 & \\
\hline Urbanization level & & & & & & & $<0.001$ \\
\hline I (The highest) & 640 & 31.87 & 188 & 37.45 & 452 & 30.01 & \\
\hline 2 & 925 & 46.07 & 254 & 50.60 & 671 & 44.56 & \\
\hline 3 & 159 & 7.92 & 20 & 3.98 & 139 & 9.23 & \\
\hline 4 (The lowest) & 284 & 14.14 & 40 & 7.97 & 244 & 16.20 & \\
\hline Level of care & & & & & & & $<0.001$ \\
\hline Hospital center & 755 & 37.60 & 249 & 49.60 & 506 & 33.60 & \\
\hline Regional hospital & 898 & 44.72 & 197 & 39.24 & 701 & 46.55 & \\
\hline Local hospital & 355 & 17.68 & 56 & 11.16 & 299 & 19.85 & \\
\hline
\end{tabular}

(Continued) 
Table I (Continued).

\begin{tabular}{|c|c|c|c|c|c|c|c|}
\hline \multirow[t]{2}{*}{ Variables } & \multicolumn{2}{|c|}{ Total } & \multicolumn{2}{|c|}{ Narcolepsy } & \multicolumn{2}{|c|}{ Controls } & \multirow[t]{2}{*}{$P$} \\
\hline & $\mathbf{n}$ & $\%$ & $\mathbf{n}$ & $\%$ & $\mathbf{n}$ & $\%$ & \\
\hline Medication for obstructive lung diseases & & & & & & & $<0.001$ \\
\hline No use & 1066 & 53.0 & 240 & 47.81 & 826 & 54.85 & \\
\hline Inhaled CS only & 250 & 12.45 & 71 & 14.14 & 179 & 11.89 & \\
\hline Bronchodilator only & 201 & 10.01 & 50 & 9.96 & $|5|$ & 10.03 & \\
\hline Inhaled CS \& bronchodilator & 170 & 8.47 & 42 & 8.37 & 128 & 8.50 & \\
\hline Oral or injected CS & 321 & 15.99 & 99 & 19.72 & 222 & 14.4 & \\
\hline
\end{tabular}

Note: $P$ : Chi-square/Fisher exact test on category variables and $t$-test on continuous variables.

Abbreviations: CNS, central nervous system; OSA, obstructive sleep apnea; CS, corticosteroid.

asthma. ${ }^{39}$ Several previous reports demonstrated the global activation of T-cells, including CD4+ $\mathrm{T}$ cells and regulatory $\mathrm{T}$ cells, in type 1 narcolepsy patients. ${ }^{40}$ Recent data regarding Pandemrix-vaccination-associated type 1 narcolepsy have shown that the vaccinated patients had enhanced T-cell immunity to orexins possibly triggered by viral antigens. ${ }^{41,42}$ These findings provide evidence for the T-cell-mediated autoimmune origin of type 1 narcolepsy. In type 2 narcolepsy, the role of the immune system is unclear. However, some studies have reported that autoimmune diseases are associated with type 2 narcolepsy. ${ }^{22,43}$ Further research is warranted to investigate the association between narcolepsy and autoimmune response.

Another study has shown that narcolepsy with hypocretin deficiency is associated with human leukocyte antigen (HLA) and T-cell receptor (TCR) polymorphisms, suggesting that an autoimmune process targets a peptide unique to hypocretin-producing neurons via specific HLApeptide-TCR interactions. ${ }^{44}$ In the present study, corticosteroid use was associated with a lower risk of narcolepsy comorbidity in patients with asthma. Since corticosteroids can suppress the autoimmune process, we hypothesize that corticosteroids may decrease the risk of narcolepsy comorbidity by the mechanism of inhibition of autoimmune processes as a collateral effect.

In the present study, higher urbanization level of residence and level of care were associated with the risk of narcolepsy comorbidity. One possible reason is that air pollutants, such as ozone, sulfur dioxide, nitrogen dioxide, and particulates, which are prevalent in the higher urbanization areas, can contribute to the onset or exacerbation of symptoms and decreased pulmonary function in patients by inducing $\mathrm{T}$ cell-mediated inflammation; ${ }^{45,46}$ This T-cell induction, consequently, may be involved in the pathogenesis of narcolepsy. This finding also suggests that socioeconomic status may play a role in the association between asthma and narcolepsy.

\section{Strengths of This Study}

This study has several strengths. First, since narcolepsy is a rare disorder, a nationwide population-based study is important for obtaining information. Second, although the diagnosis of narcolepsy in the NHIRD has not been previously validated, the diagnoses of several respiratory diseases, such as asthma, ${ }^{29}$ sleep apnea, ${ }^{30}$ pneumonia, ${ }^{30}$ and tuberculosis, ${ }^{31}$ have been validated. Third, since the NHIRD contains the records of medications for asthma, we analyzed the effects of corticosteroids and bronchodilators and inferred that the appropriate use of inhaled corticosteroids for asthma patients may lower the subsequent risk of narcolepsy comorbidity.

\section{Limitations of This Study}

This study had some limitations. First, the diagnoses of asthma and narcolepsy were determined based on the ICD9-CM codes instead of validated structural diagnostic instruments. Moreover, we could not identify the types of narcolepsy in our study. However, the diagnosis of asthma was previously validated, ${ }^{29}$ and we used strict criteria to identify cases of narcolepsy in our database. The distinction between type 1 (with cataplexy) and type 2 narcolepsy (without cataplexy) could not be identified using the ICD9-CM codes. In addition, idiopathic hypersomnia, severe sleep apnea, sleep deprivation, and circadian rhythm disorders may be recorded as narcolepsy, whereas disturbed night sleep in patients with narcolepsy may have been recorded as insomnia. Nonetheless, the National Health Insurance Administration in Taiwan has strived to 
Table 2 Multiple Logistic Regression Analysis of Factors Contributing to Narcolepsy Comorbidity

\begin{tabular}{|c|c|c|c|c|c|c|c|c|}
\hline Variables & Crude OR & $95 \% \mathrm{Cl}$ & $95 \% \mathrm{Cl}$ & $\boldsymbol{P}$ & Adjusted OR & $95 \% \mathrm{Cl}$ & $95 \% \mathrm{Cl}$ & $\boldsymbol{P}$ \\
\hline Asthma & 3.086 & 2.056 & 4.631 & $<0.001$ & 3.181 & 2.048 & 4.941 & $<0.001$ \\
\hline \multicolumn{9}{|l|}{ Sex } \\
\hline Male & 1.000 & 0.814 & 1.229 & 0.905 & 0.998 & 0.800 & 1.244 & 0.983 \\
\hline Female & Reference & & & & Reference & & & \\
\hline \multicolumn{9}{|l|}{ Age group (years) } \\
\hline $6-11$ & Reference & & & & Reference & & & \\
\hline $12-19$ & 1.216 & 0.415 & 3.057 & 0.815 & 0.925 & 0.547 & 1.565 & 0.772 \\
\hline $20-44$ & 0.578 & 0.208 & 1.612 & 0.295 & 0.848 & 0.510 & 1.412 & 0.527 \\
\hline $45-64$ & 1.019 & 0.365 & 2.847 & 0.971 & 0.911 & 0.534 & 1.552 & 0.730 \\
\hline$\geq 65$ & 1.896 & 0.773 & 4.906 & 0.187 & 0.968 & 0.579 & 1.619 & 0.901 \\
\hline \multicolumn{9}{|l|}{ Insurance premium (NT\$) } \\
\hline$<18,000$ & Reference & & & & Reference & & & \\
\hline $18,000-34,999$ & 0.000 & - & - & 0.991 & 0.000 & - & - & 0.997 \\
\hline$\geq 35,000$ & 0.000 & - & - & 0.991 & 0.000 & - & - & 0.997 \\
\hline Atopic dermatitis & 0.000 & - & - & 0.997 & 0.000 & - & - & 0.999 \\
\hline Allergic rhinitis & 0.000 & - & - & 0.997 & 0.000 & - & - & 0.999 \\
\hline Psychiatric disorders & 2.979 & 2.189 & 4.055 & $<0.001$ & 3.272 & 2.338 & 4.581 & $<0.001$ \\
\hline CNS infection & 3.361 & 1.103 & 11.951 & 0.034 & 2.296 & 0.603 & 8.742 & 0.223 \\
\hline Cerebral palsy & 2.648 & 0.955 & 7.339 & 0.061 & 3.001 & 0.988 & 9.120 & 0.053 \\
\hline OSA & 16.394 & 5.600 & 47.994 & $<0.001$ & 14.245 & 4.110 & 49.368 & $<0.001$ \\
\hline Insomnia & 9.826 & 4.604 & 20.970 & $<0.001$ & 9.635 & 4.272 & 21.728 & $<0.001$ \\
\hline Influenza & 0.135 & 0.018 & 1.001 & 0.051 & 0.228 & 0.030 & 1.746 & 0.155 \\
\hline Autoimmune diseases & 1.202 & 0.375 & 3.848 & 0.757 & 1.097 & 0.326 & 3.698 & 0.881 \\
\hline \multicolumn{9}{|l|}{ Urbanization level } \\
\hline I (The highest) & 2.537 & 1.744 & 3.692 & $<0.001$ & 2.125 & 1.374 & 3.285 & 0.001 \\
\hline 2 & 2.309 & 1.604 & 3.324 & $<0.001$ & 2.214 & 1.474 & 3.320 & $<0.001$ \\
\hline 3 & 0.878 & 0.494 & 1.561 & 0.657 & 0.904 & 0.495 & 1.651 & 0.743 \\
\hline 4 (The lowest) & Reference & & & & Reference & & & \\
\hline \multicolumn{9}{|l|}{ Level of care } \\
\hline Hospital center & 2.627 & 1.902 & 2.630 & $<0.001$ & 1.749 & 1.206 & 2.537 & 0.003 \\
\hline Regional hospital & 1.500 & 1.083 & 2.079 & 0.015 & 1.252 & 0.884 & 1.773 & 0.207 \\
\hline Local hospital & Reference & & & & Reference & & & \\
\hline \multicolumn{9}{|l|}{ Medication for obstructive lung diseases } \\
\hline No use & Reference & & & & Reference & & & \\
\hline Inhaled CS only & 0.498 & 0.241 & 0.865 & $<0.001$ & 0.337 & 0.198 & 0.785 & $<0.001$ \\
\hline Bronchodilator only & 0.972 & 0.753 & 1.184 & 0.186 & 0.803 & 0.660 & 1.026 & 0.083 \\
\hline Inhaled CS \& bronchodilator & - & - & - & - & - & - & - & - \\
\hline Oral or injected CS & - & - & - & - & - & - & - & - \\
\hline
\end{tabular}

Note: Location not included given collinearity with urbanization level.

Abbreviations: OR, odds ratio; $\mathrm{Cl}$, confidence interval; Adjusted OR, Adjusted OR: Adjusted variables as sex, age, insured premium, atopic dermatitis, allergic rhinitis, psychiatric disorders, CNS infection, cerebral palsy, OSA, insomnia, influenza, autoimmune diseases, urbanization level, level of care. 
Table 3 Association Between Medication for Obstructive Lung Diseases in Asthma Patients and Narcolepsy Comorbidity

\begin{tabular}{|c|c|c|c|c|c|c|c|c|}
\hline Medication for Obstructive Lung Diseases & Crude OR & $95 \% \mathrm{Cl}$ & $95 \% \mathrm{Cl}$ & $\boldsymbol{P}$ & Adjusted OR & $95 \% \mathrm{Cl}$ & $95 \% \mathrm{Cl}$ & $\boldsymbol{P}$ \\
\hline No use & Reference & & & & Reference & & & \\
\hline Inhaled corticosteroid only & 0.442 & 0.231 & 0.598 & $<0.001$ & 0.465 & 0.250 & 0.634 & $<0.001$ \\
\hline Bronchodilator only & 0.857 & 0.669 & 0.997 & 0.048 & 0.870 & 0.683 & 1.076 & 0.075 \\
\hline Inhaled corticosteroid and bronchodilator & - & - & - & - & - & - & - & - \\
\hline Oral or injected corticosteroid & - & - & - & - & - & - & - & - \\
\hline
\end{tabular}

Note: Location not included given collinearity with urbanization level.

Abbreviations: OR, odds ratio; $\mathrm{Cl}$, confidence interval; Adjusted OR, Adjusted variables as sex, age, asthma, insured premium, atopic dermatitis, allergic rhinitis, psychiatric disorders, CNS infection, cerebral palsy, OSA, insomnia, influenza, autoimmune diseases, urbanization level, level of care, medication for obstructive lung diseases; CNS, central nervous system; OSA, obstructive sleep apnea; CS, corticosteroid.

determine the accuracy of diagnoses in the database. Furthermore, we enrolled only narcoleptic patients diagnosed by board-certified sleep medicine specialists. Second, the authors could not measure some factors that may have influenced the results. For instance, coffee consumption and cigarette smoking, which were not assessed in the database, are associated with daytime sleepiness and airway stimulation. Third, the average age at narcolepsy diagnosis was higher in this study than in studies from other countries, and the delayed diagnosis of narcolepsy in Taiwan should be considered. Poor patient insights and low clinician awareness of this disorder may explain this finding. Further verification is required to generalize our findings.

\section{Conclusion}

This study demonstrated a significantly higher proportion of previous asthma diagnosis in patients with narcolepsy. Compared with not using medication, the use of inhaled corticosteroids was associated with a lower risk of narcolepsy comorbidity in patients with asthma, and no significant difference was observed for the use of bronchodilators. Clinicians should be aware of the possibility of narcolepsy following the diagnosis of asthma. Further studies are needed to explore the underlying mechanisms of these two diseases.

\section{Abbreviations}

CI, confidence interval; CKD, chronic kidney disease; CNS, central nervous system; CS, corticosteroid; HLA, human leukocyte antigen; ICD, International Classification of Diseases; LHID, Longitudinal Health Insurance Database; NHIRD, National Health Insurance Research Database; OR, Odds ratio; OSA, obstructive sleep apnea; TCR, T-cell receptor.

\section{Acknowledgments}

This study is based in part on data from the National Health Insurance Research Database provided by the Bureau of National Health Insurance of the Department of Health, Taiwan, and managed by National Health Research Institutes, Taiwan. The interpretation and conclusions contained in this article do not represent those of the Bureau of National Health Insurance, the Department of Health, or the National Health Research Institutes. All data accessed complied with relevant data protection and privacy regulations. Tien-Yu Chen and Vincent Yi-Fong Su contributed equally as first authors. Wu-Chien Chien and Nian-Sheng Tzeng contributed equally as corresponding authors.

\section{Funding}

This work was supported by the Tri-Service General Hospital Research Foundation (TSGH-C108-003, TSGHC108-151, TSGH-B-109-010, TSGH-D-109197, TSGHB-110-012, TSGH-D-110176, and TSGH-E-110240), the Taoyuan Armed Forces General Hospital (TYAFGHA-110020), and the Medical Affairs Bureau, Ministry of Defense of Taiwan (MND-MAB-110-087).

\section{Disclosure}

The authors declare no conflicts of interest for this work.

\section{References}

1. Murray TJ, Foley A. Narcolepsy. Can Med Assoc J. 1974;110 (1):63-66.

2. Zeman A, Britton T, Douglas N, et al. Narcolepsy and excessive daytime sleepiness. BMJ. 2004;329(7468):724-728.

3. Dauvilliers Y, Arnulf I, Mignot E. Narcolepsy with cataplexy. Lancet. 2007;369(9560):499-511.

4. Rocca FL, Pizza F, Ricci E, Plazzi G. Narcolepsy during childhood: an update. Neuropediatrics. 2015;46(3):181-198.

5. Postiglione E, Antelmi E, Pizza F, Lecendreux M, Dauvilliers Y, Plazzi G. The clinical spectrum of childhood narcolepsy. Sleep Med Rev. 2018;38:70-85. 
6. Tzeng NS, Hsing SC, Chung CH, et al. The risk of hospitalization for motor vehicle accident injury in narcolepsy and the benefits of stimulant use: a nationwide cohort study in Taiwan. J Clin Sleep Med. 2019;15(6):881-889.

7. Hung YY, Yang LH, Stubbs B, et al. Efficacy and tolerability of deep transcranial magnetic stimulation for treatment-resistant depression: a systematic review and meta-analysis. Prog Neuropsychopharmacol Biol Psychiatry. 2020;99:109850.

8. Bartels EC, Kusakcioglu O. Narcolepsy: a possible cause of automobile accidents. Lahey Clin Found Bull. 1965;14(1):21-26.

9. Grubb TC. Narcolepsy and highway accidents. JAMA. 1969;209 (11): 1720 .

10. Thorpy MJ, Krieger AC. Delayed diagnosis of narcolepsy: characterization and impact. Sleep Med. 2014;15(5):502-507.

11. Frauscher B, Ehrmann L, Mitterling T, et al. Delayed diagnosis, range of severity, and multiple sleep comorbidities: a clinical and polysomnographic analysis of 100 patients of the Innsbruck narcolepsy cohort. J Clin Sleep Med. 2013;9(8):805-812.

12. Luca G, Haba-Rubio J, Dauvilliers Y, et al. Clinical, polysomnographic and genome-wide association analyses of narcolepsy with cataplexy: a European Narcolepsy Network study. J Sleep Res. 2013;22(5):482-495.

13. Aldrich MS. Automobile accidents in patients with sleep disorders. Sleep. 1989;12(6):487-494.

14. Hong S, Son DK, Lim WR, et al. The prevalence of atopic dermatitis, asthma, and allergic rhinitis and the comorbidity of allergic diseases in children. Environ Health Toxicol. 2012;27:e2012006.

15. Grize L, Gassner M, Wuthrich B, et al. Trends in prevalence of asthma, allergic rhinitis and atopic dermatitis in 5-7-year old Swiss children from 1992 to 2001. Allergy. 2006;61(5):556-562.

16. Yan DC, Ou LS, Tsai TL, Wu WF, Huang JL. Prevalence and severity of symptoms of asthma, rhinitis, and eczema in 13- to 14-year-old children in Taipei, Taiwan. Ann Allergy Asthma Immunol. 2005;95 (6):579-585.

17. Cukic V, Lovre V, Dragisic D. Sleep disorders in patients with bronchial asthma. Mater Sociomed. 2011;23(4):235-237.

18. Bernard-Valnet R, Yshii L, Queriault C, et al. CD8 T cell-mediated killing of orexinergic neurons induces a narcolepsy-like phenotype in mice. Proc Natl Acad Sci USA. 2016;113(39):10956-10961.

19. Latorre D, Kallweit U, Armentani E, et al. T cells in patients with narcolepsy target self-antigens of hypocretin neurons. Nature. 2018;562(7725):63-68.

20. Martinez-Orozco FJ, Vicario JL, Villalibre-Valderrey I, De Andres C, Fernandez-Arquero M, Peraita-Adrados R. Narcolepsy with cataplexy and comorbid immunopathological diseases. J Sleep Res. 2014;23(4):414-419.

21. Aydinoz S, Huang YS, Gozal D, Inocente CO, Franco P, KheirandishGozal L. Allergies and disease severity in childhood narcolepsy: preliminary findings. Sleep. 2015;38(12):1981-1984.

22. Alomar M, Almeneessier AS, Olaish AH, Alshiban A, Alomar A, BaHammam AS. Immune-mediated comorbidities in Saudi patients with narcolepsy. Nat Sci Sleep. 2019;11:35-43.

23. Huang HL, Ho SY, Li CH, et al. Bronchial asthma is associated with increased risk of chronic kidney disease. BMC Pulm Med. 2014; $14: 80$.

24. Tang YJ, Ho SY, Chu FY, et al. Is Zolpidem associated with increased risk of fractures in the elderly with sleep disorders? A nationwide case cross-over study in Taiwan. PLoS One. 2015;10 (12):e0146030.

25. Chen TY, Winkelman JW, Mao WC, Liu CL, Hsu CY, Wu CS. The use of benzodiazepine receptor agonists and the risk of hospitalization for pneumonia: a nationwide population-based nested case-control study. Chest. 2018;153(1):161-171.

26. Tzeng NS, Chang HA, Chung $\mathrm{CH}$, et al. Increased risk of psychiatric disorders in allergic diseases: a nationwide, population-based, cohort study. Front Psychiatry. 2018;9:133.
27. Tseng WS, Chien WC, Chung CH, Chou YC, Tzeng NS. Risk of sleep disorders in patients with decompression sickness: a nationwide, population-based study in Taiwan. Psychiatr Danub. 2019;31(2):172-181.

28. Chen TY, Liu CT, Chung CH, Hung SL, Chien WC, Chen JH. Bariatric surgery may provide better protection than uvulopalatopharyngoplasty against major adverse cardiovascular events in obese patients with obstructive sleep apnea. Surg Obes Relat Dis. 2021;17 (4):780-791.

29. Su VY, Yang KY, Yang YH, et al. Use of ICS/LABA combinations or LAMA is associated with a lower risk of acute exacerbation in patients with coexistent COPD and asthma. J Allergy Clin Immunol Pract. 2018;6(6):1927-1935.

30. Su VY, Liu CJ, Wang HK, et al. Sleep apnea and risk of pneumonia: a nationwide population-based study. Can Med Assoc J. 2014;186 (6):415-421.

31. Su VY, Su WJ, Yen YF, et al. Statin use is associated with a lower risk of TB. Chest. 2017;152(3):598-606.

32. Chang CY, Chen WL, Liou YF, et al. Increased risk of major depression in the three years following a femoral neck fracture-a national population-based follow-up study. PLoS One. 2014;9(3): e89867.

33. Chang YL, Ko HK, Lu MS, et al. Independent risk factors for death in patients admitted for asthma exacerbation in Taiwan. NPJ Prim Care Respir Med. 2020;30(1):7.

34. Parimon T, Chien JW, Bryson CL, McDonell MB, Udris EM, Au DH. Inhaled corticosteroids and risk of lung cancer among patients with chronic obstructive pulmonary disease. Am J Respir Crit Care Med. 2007;175(7):712-719.

35. Huang YC, Chan WC, Wang JD, Fu LS, Tsan YT. Association between dry eye disease and asthma: a nationwide population-based study. PeerJ. 2018;6:e5941.

36. Kok VC, Horng JT, Huang HK, Chao TM, Hong YF. Regular inhaled corticosteroids in adult-onset asthma and the risk for future cancer: a population-based cohort study with proper person-time analysis. Ther Clin Risk Manag. 2015;11:489-499.

37. Wang WC, Lu ML, Chen VC, et al. Asthma, corticosteroid use and schizophrenia: a nationwide population-based study in Taiwan. PLoS One. 2017;12(3):e0173063.

38. Castillo EF, Zheng H, Yang XO. Orchestration of epithelial-derived cytokines and innate immune cells in allergic airway inflammation. Cytokine Growth Factor Rev. 2018;39:19-25.

39. Arora P, Ansari SH. Role of various mediators in inflammation of asthmatic airways. In: Pereira C, editor. Asthma-Biological Evidences. London, United Kingdom: IntechOpen; 2019:1-14.

40. Lecendreux M, Churlaud G, Pitoiset F, et al. Narcolepsy type 1 is associated with a systemic increase and activation of regulatory T cells and with a systemic activation of global T cells. PLoS One. 2017;12(1):e0169836.

41. Vuorela A, Freitag TL, Leskinen K, et al. Enhanced influenza A H1N1 T cell epitope recognition and cross-reactivity to protein-O-mannosyltransferase 1 in Pandemrix-associated narcolepsy type 1. Nat Commun. 2021;12(1):2283.

42. Cogswell AC, Maski K, Scammell TE, Tucker D, Orban ZS, Koralnik IJ. Children with narcolepsy type 1 have increased T-cell responses to orexins. Ann Clin Transl Neurol. 2019;6(12):2566-2572.

43. Barateau L, Lopez R, Arnulf I, et al. Comorbidity between central disorders of hypersomnolence and immune-based disorders. Neurology. 2017;88(1):93-100.

44. De la Herran-arita AK, Garcia-Garcia F. Narcolepsy as an immune-mediated disease. Sleep Disord. 2014;2014:792687.

45. Guarnieri M, Balmes JR. Outdoor air pollution and asthma. Lancet. 2014;383(9928):1581-1592.

46. Mortimer KM, Neas LM, Dockery DW, Redline S, Tager IB. The effect of air pollution on inner-city children with asthma. Eur Respir J. 2002;19(4):699-705. 


\section{Publish your work in this journal}

Nature and Science of Sleep is an international, peer-reviewed, open access journal covering all aspects of sleep science and sleep medicine, including the neurophysiology and functions of sleep, the genetics of sleep, sleep and society, biological rhythms, dreaming, sleep disorders and therapy, and strategies to optimize healthy sleep.

Submit your manuscript here: https://www.dovepress.com/nature-and-science-of-sleep-journal
The manuscript management system is completely online and includes a very quick and fair peer-review system, which is all easy to use. Visit http://www.dovepress.com/testimonials.php to read real quotes from published authors. 